\title{
One-year outcome with a bovine pericardial valve
}

Jinmiao Chen, MD, PhD, ${ }^{\mathrm{a}, \mathrm{b}}$ Chen He, MD, ${ }^{\mathrm{a}, \mathrm{b}}$ Minzhi Lv, MD, ${ }^{\mathrm{c}}$ Yingqiang Guo, MD, ${ }^{\mathrm{d}}$ Liang Tao, MD, Tao Hong, MD, PhD, ${ }^{\mathrm{a}, \mathrm{b}}$ and Chunsheng Wang, MD, ${ }^{\mathrm{a}, \mathrm{b}}$ the Working Group*

\section{ABSTRACT}

Objectives: To evaluate the safety and effectiveness of a novel surgical bovine pericardial valve for aortic and mitral valve replacements.

Methods: Between March 2016 and October 2017, 197 patients (mean age, $66.9 \pm 4.9$ years; $40.6 \%$ were women) underwent aortic valve replacement and mitral valve replacement and were implanted with the Cingular bovine pericardial valve (Shanghai Cingular Biotech Corporation, Shanghai, China) in a prospective, multicenter, single-arm trial in China. A total of 161 aortic and 49 mitral prostheses were implanted. Patients were followed up to 1 year. The primary end point was the 1-year overall rate of valve-related complications, including thromboembolic event, valve thrombosis, major hemorrhage event, major perivalvular leak, and prosthetic valve endocarditis.

Results: The 1-year overall rate of valve-related complications was $0.5 \%$ (95\% confidence interval, $0.1 \%-3.7 \%$ ). The 1 -year survival was $96.4 \%$. The mean gradient and effective orifice area for aortic prostheses at 1 year postoperatively were $12.8 \pm 4.4 \mathrm{~mm} \mathrm{Hg}$ and $1.9 \pm 0.3 \mathrm{~cm}^{2}$, respectively. Particularly, the mean gradients and effective orifice area for $19 \mathrm{~mm}$ and $21 \mathrm{~mm}$ sizes of aortic prostheses at 1 year were $17.0 \pm 3.8 \mathrm{~mm} \mathrm{Hg}$ and $1.6 \pm 0.2 \mathrm{~cm}^{2}, 13.1 \pm 4.0 \mathrm{~mm} \mathrm{Hg}$ and $1.8 \pm 0.1 \mathrm{~cm}^{2}$, respectively. Patient-prosthesis mismatch occurred in only $1.3 \%$ patients for aortic valve implantation at 1 month. No structural valve deterioration and no endocarditis occurred.

Conclusions: The Cingular bovine pericardial valve was safe and effective for surgical aortic and mitral valve replacement. The 1-year rate of valve-related complications was very low. Early hemodynamic performance was excellent even for the small aortic root. (JTCVS Open 2020;2:1-11)

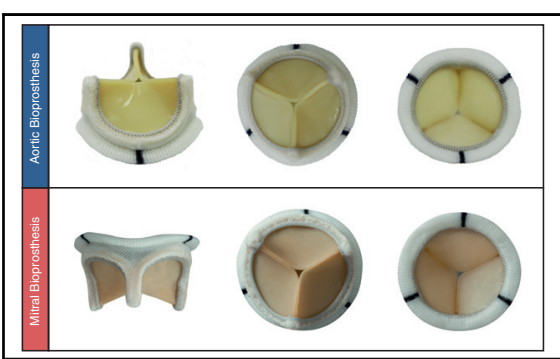

The Cingular bovine pericardial valves, including aortic and mitral bioprosthesis. Left panel, lateral view. Middle panel, outflow view. Right panel, inflow view.

\section{CENTRAL MESSAGE}

The Cingular bovine pericardial valve was safe and effective for surgical aortic and mitral valve replacement.

\section{PERSPECTIVE}

The Cingular bovine pericardial valve was safe and effective for surgical aortic and mitral valve replacement. The 1-year overall rate of valverelated complications was very low. Early hemodynamic performance was excellent even for the small aortic root.

See Commentary on page 12.
- Video clip is available online.

Bovine pericardial valves offer excellent longevity and reliable hemodynamic performance without long-term anticoagulation treatment. ${ }^{1-6}$ With an increasingly aging population, bovine pericardial valves will be selected

\footnotetext{
From the Departments of ${ }^{a}$ Cardiac Surgery and ${ }^{c}$ Biostatistics, Zhongshan Hospital, Fudan University, Shanghai, China; ${ }^{b}$ Shanghai Engineering Research Center of Heart Valve, Shanghai, China; ${ }^{\mathrm{d}}$ Department of Cardiac Surgery, West China Hospital, Sichuan University, Sichuan Province, China; and ${ }^{\mathrm{e}}$ Department of Cardiac Surgery, Wuhan Asia Heart Hospital, Hubei Province, China.

This work was supported by the Shanghai Municipal Commission of Health and Family Planning (grant No. 201540385), the Shanghai Leading Talent Project (grant No. 14XD1401000), and Joint Project Funding for Major Diseases in Shanghai (grant No. 2014ZYJB0402). Shanghai Cingular Biotech Corporation provided the study valve free of charge.

Drs Chen and He contributed equally to this article.

* The Working Group included Xinmin Zhou, MD, Tianxiang Gu, MD, Lai Wei, MD, $\mathrm{PhD}$, Jiahui Fu, MPH, Yao Wang, MD, and Yu Shi, MD.
}

more and more as the preferred choice for surgical valve replacement. The durability and effective orifice area (EOA) were the major features of the bioprosthesis and continuous modifications were made. ${ }^{7-9}$

The Cingular bovine pericardial valve (Shanghai Cingular Biotech Corporation, Shanghai, China) was built on the well-established Carpentier-Edwards Perimount (Edwards Lifesciences, Irvine, Calif) valve and incorporated certain

Received for publication March 24, 2020; revisions received March 24, 2020 accepted for publication April 7, 2020.

Address for reprints: Tao Hong, MD, PhD, and Chunsheng Wang, MD, Department of Cardiac Surgery, Zhongshan Hospital, Fudan University, 180 Fenglin Rd, Shangha 200032, China (E-mail: hong.tao@zs-hospital.sh.cn and wang.chunsheng@ zs-hospital.sh.cn).

2666-2736

Copyright $(C) 2020$ The Authors. Published by Elsevier Inc. on behalf of The American Association for Thoracic Surgery. This is an open access article under the CC BY-NCND license (http://creativecommons.org/licenses/by-nc-nd/4.0/).

https://doi.org/10.1016/j.xjon.2020.04.002 


\section{Abbreviations and Acronyms \\ AVR = aortic valve replacement \\ $\mathrm{CABG}=$ coronary artery bypass graft \\ EOA = effective orifice area \\ MVR = mitral valve replacement \\ NYHA $=$ New York Heart Association \\ PPM = patient-prosthesis mismatch}

innovations for the purpose of improving the valve stability and durability, reducing the possibility and the extent of triangular leaflet opening, and increasing the EOA. The performance of this study valve has been evaluated in juvenile sheep. ${ }^{10}$ The purpose of this prospective, multicenter, single-arm trial was to evaluate the safety and effectiveness of this study valve for surgical aortic valve replacement (AVR) and mitral valve replacement (MVR) in humans. We herein reported the 1-year outcomes of this trial.

\section{METHODS AND MATERIALS Study Design}

A prospective, 5-center, single-arm clinical trial (ClinicalTrials.gov identifier: NCT02755220) was conducted to evaluate the safety and effectiveness of the Cingular bovine pericardial valve (Figure 1) in accordance with the principles of the Declaration of Helsinki and all applicable laws and regulations. The protocol and all amendments were reviewed by an Institutional Review Board or Ethics Committee at each investigational site. Written informed consent was obtained from all patients before surgery.

\section{Patient Selection}

Patients were enrolled by surgeons at each investigational site based on indications for surgical AVR or MVR, an appropriate risk profile and surgical preference for a bioprosthesis. The inclusion criteria were as follows: patients with heart valve disease requiring surgical replacement as indicated in the preoperative evaluation, patients aged between 60 and 85 years, patients with preoperative heart function less than New York Heart Association (NYHA) functional class IV, patients who signed the informed consent before surgery, and patients who agreed to finish the follow-up. The exclusion criteria were as follows: patients had prior valve replacement, patients who required concomitant tricuspid or pulmonary valve replacement, patients who required concomitant coronary artery bypass grafting $(\mathrm{CABG})$, patients with active infective endocarditis or drug abuse, patients with a life time expectancy $<12$ months, and patients who were unable to follow anticoagulation treatment. Patients requiring CABG were excluded because concomitant $\mathrm{CABG}$ may complicate the procedure and antiplatelet therapy after $\mathrm{CABG}$ may contaminate the primary outcomes such as thromboembolic event, valve thrombosis, and major hemorrhage event.

\section{Surgical Valve Replacement}

Surgical AVR or MVR was routinely performed using median sternotomy or upper hemisternotomy, a standard cardiopulmonary bypass technique with ascending aortic and venous cannulation, mild hypothermia, and cold crystalloid cardioplegic arrest. Using the specifically designed sizers for the Cingular bovine pericardial valve, the appropriate bioprosthesis size was carefully chosen for each patient. All valves were implanted using interrupted, pledgeted, mattressed sutures. Postoperative anticoagulation therapy was recommended in accordance with the Guidelines for Management of Patients with Valvular Heart Disease. ${ }^{11,12}$ Briefly, anticoagulation with warfarin was adopted to achieve an international normalized ratio target of 2.5 (range, 2.0-3.0) for 3 to 6 months after surgery. In the patient with atrial fibrillation, lifelong warfarin therapy was indicated to achieve an international normalized ratio of 2 to 3 .

\section{Study End Points}

The primary end point for the trial was the overall rate of valve-related complications at 1 year after valve implantation, including thromboembolic event, valve thrombosis, major hemorrhage event, major perivalvular leak, and prosthetic valve endocarditis, according to the update of objective

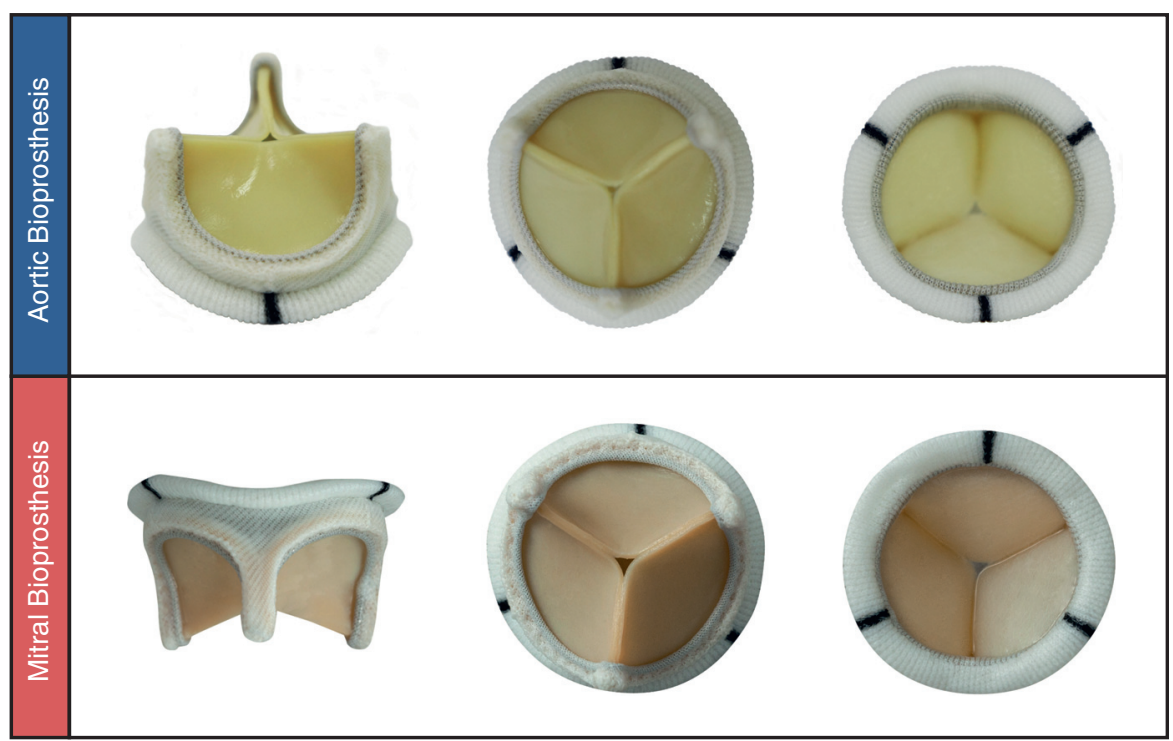

FIGURE 1. The Cingular bovine pericardial valves (Shanghai Cingular Biotech Corporation, Shanghai, China), including aortic and mitral bioprosthesis. Left panel, Lateral view. Middle panel, Outflow view. Right panel, Inflow view. 


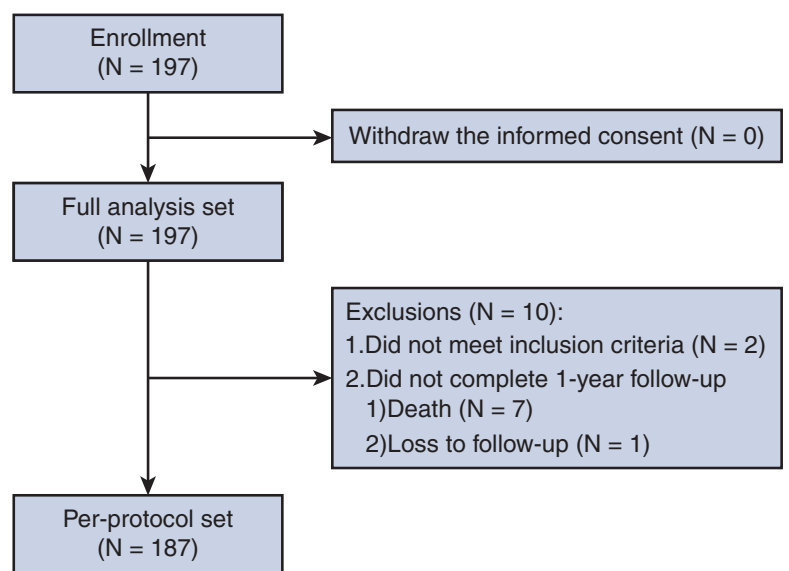

FIGURE 2. Study flow of patients through the clinical trial of Cingular bovine pericardial valves (Shanghai Cingular Biotech Corporation, Shanghai, China).

performance criteria for clinical evaluation of new heart valve prostheses. ${ }^{13}$ The secondary end points were the procedural success, echocardiographic hemodynamic performance, improvement in NYHA functional class, allcause mortality, structural valve deterioration, and valve-related reoperation at 1 year according to the guidelines for reporting mortality and morbidity after heart valve surgery. ${ }^{14}$ The study protocol was guided by ISO 5840-2:2015.

\section{Echocardiographic Assessment}

Patients were followed-up by transthoracic Doppler echocardiography at 1 month and 1 year postoperatively. The modified Bernoulli equation was used to calculate mean gradient across the bioprosthetic valve. The EOA was calculated by the continuity equation and indexed to body surface area to assess the presence of patient-prosthesis mismatch (PPM) for aortic valve. PPM was considered not clinically significant if the indexed EOA was $>0.85 \mathrm{~cm}^{2} / \mathrm{m}^{2}$; PPM was considered moderate if the indexed EOA was $>0.65 \mathrm{~cm}^{2} / \mathrm{m}^{2}$ and $\leq 0.85 \mathrm{~cm}^{2} / \mathrm{m}^{2}$; and PPM was considered severe if the indexed EOA was $\leq 0.65 \mathrm{~cm}^{2} / \mathrm{m}^{2}{ }^{15,16}$

\section{Data Acquisition and Follow-up}

Data were prospectively collected by the respective study coordinator at each participating center. The trial was monitored by an independent Contract Research Organization. All suspected end point events were adjudicated by an independent Clinical Events Committee based on patient-level source documents obtained from each investigational site. Hemodynamic performance data were evaluated by an independent echocardiography core laboratory (Department of Echocardiography, Zhongshan Hospital, Fudan University). The data management and statistical analyses were handled by the National Center for Cardiovascular Diseases

TABLE 1. Surgical volume at each participating centers

\begin{tabular}{lr}
\hline \multicolumn{1}{c}{ Center } & n \\
\hline Zhongshan Hospital, Fudan University & 80 \\
West China Hospital, Sichuan University & 80 \\
Wuhan Asia Heart Hospital & 28 \\
The First Hospital of China Medical University & 7 \\
The Second Xiangya Hospital of Central South University & 2 \\
\hline
\end{tabular}

TABLE 2. Baseline characteristics of all patients $(N=197)$

\begin{tabular}{lc}
\hline \multicolumn{1}{c}{ Parameter } & Result \\
\hline Age (y) & $66.9 \pm 4.9$ \\
Female sex & $80(40.6)$ \\
BMI & $23.1 \pm 3.5$ \\
NYHA functional class & \\
$\quad$ II & $51(25.9)$ \\
III & $144(73.1)$ \\
IV & $2(1.0)$ \\
\hline Systemic hypertension & $74(37.6)$ \\
Coronary artery disease & $8(4.1)$ \\
\hline COPD & $29(14.7)$ \\
Diabetes mellitus & $9(4.6)$ \\
\hline STS predicted risk of mortality (\%) & $1.6 \pm 1.1$ \\
STS predicted risk of morbidity or mortality (\%) & $12.9 \pm 5.5$ \\
\hline Logistic EuroSCORE II (\%) & $2.8 \pm 2.3$ \\
\hline Values are presented as mean \pm standard deviation or n (\%). BMI, Body mass index; \\
NYHA, New York Heart Association; COPD, chronic obstructive pulmonary disease; \\
STS, Society of Thoracic Surgeons; EuroSCORE, European System for Cardiac Oper- \\
ative Risk Evaluation.
\end{tabular}

(Beijing, China). The clinical follow-up data were collected at discharge, 1 month, 3 months, 6 months, and 1 year postoperatively.

\section{Statistical Analysis}

The sample size calculation was according to the published reference in which the overall rate of valve-related complications was about $2.9 \%$ per patient-year. ${ }^{13}$ In addition, the average level of valve-related complication rate was about $9.0 \%$ per patient-year based on data from the premarket approvals of Carpentier-Edwards Perimount valve (P860057), Mitroflow aortic pericardial valve (P060038) (Sorin Group USA, Arvada, Colo) and Trifecta valve (P100029) (St Jude Medical, St Paul, Minn). On this basis, we assumed that the overall rate of valverelated complications was $2.9 \%$ per patient-year for the Cingular bovine pericardial valve. Sample size calculation was performed with a 2 -sided $\alpha$ level of 0.05 and $80 \%$ power. On the basis of these assumptions, 135 Cingular bovine pericardial valves would be required. The sample size was adjusted for loss to follow-up of up to $10 \%$ and the requirements of the China Food and Drug Administration regulations, leading to a sample size of 197 patients.

Full analysis set was defined as patients provided informed consent and received the Cingular bovine pericardial valve implantation. Per-protocol set was defined as patients matched the inclusion criteria and completed 1-year primary end point assessment (Figure 2). Safety analysis set was defined as patients received the Cingular bovine pericardial valve implantation and at least 1 safety assessment.

Continuous variables were summarized as mean \pm standard deviation. Categorical variables were summarized as the number and percentage of subjects in each category. The Kaplan-Meier method was used to estimate the rate and $95 \%$ confidence interval $(\mathrm{CI})$ of valve-related complications and survival rate 1 year after valve implantation. Sensitivity analysis was performed using tipping point method for adjustment of missing primary end point assessments due to death and loss to follow-up. We did post hoc subgroup analyses of different surgery types for several key outcomes. The post hoc subgroup analysis was an exploratory result due to the insufficient sample size of each subgroup. Tests were performed using SAS 9.4 (SAS Institute Inc, Cary, NC). 


\section{RESULTS}

\section{Baseline Patient Characteristics}

A total of 197 patients at 5 centers were enrolled in this clinical trial (Table 1). Patient baseline characteristics were presented in Table 2 and were classified according to surgical type in Table 3. The mean age was $66.9 \pm 4.9$ years (range, $60-84$ years) and $40.6 \%$ were women. Associated comorbidities included systemic hypertension $(37.6 \%)$, chronic obstructive pulmonary disease $(14.7 \%)$, and diabetes mellitus $(4.6 \%)$. The mean Society of Thoracic Surgeons Predicted Risk of Mortality score was $1.6 \% \pm 1.1 \%$ and the mean Logistic European System for Cardiac Operative Risk Evaluation II score was $2.8 \% \pm 2.3 \%$.

\section{Intraoperative Findings}

The intraoperative findings were presented in Table 4 and Table 3. Procedural success was achieved in $100 \%$ patients. AVR, MVR, and double valve replacement were performed in $75.1 \%$ (148 out of 197 ), $18.3 \%$ (36 out of 197 ), and $6.6 \%$ (13 out of 197) of patients, respectively. Full sternotomy was employed in $98.5 \%$ of cases and upper hemisternotomy in $1.5 \%$ of cases. Totally, 161 aortic and 49 mitral bioprostheses were implanted. The bioprosthetic sizes were summarized in Table 4. For the aortic prostheses, $37.8 \%$ patients received the $19 \mathrm{~mm}$ and $21 \mathrm{~mm}$ sizes. The concomitant procedures were also listed in Table 4 . The mean aortic crossclamp time and cardiopulmonary bypass time were $70.2 \pm 26.2$ minutes and $102.8 \pm 30.9$ minutes, respectively.

\section{Primary Outcomes}

Overall, 95.9\% (189 out of 197) of patients completed the primary end point assessments at 1 year after valve implantation. In the full analysis set, the overall rate of valve-related complications was $0.5 \%$ ( 1 out of 189 , $\left.\mathrm{n}_{\text {miss }}=8\right)(95 \%$ CI, $0.1 \%-3.7 \% ; P<.001)$ (Table 3 and Table 5). Valve thrombosis occurred in one patient receiving MVR with postoperative atrial fibrillation. Using sensitivity analysis with tipping point method for adjustment of missing primary end point assessments due to death and loss to follow-up, the overall rate of valve-related complications was also lower than the pre-set point $9.0 \%$ (Table 6). Furthermore, the overall rate of valve-related complications in the per-protocol set was $0.5 \%$ ( 1 out of 187 ) $(95 \%$ CI, $0.1 \%-3.7 \%$;

TABLE 3. Baseline characteristics, intraoperative data, and primary outcomes classified by surgical type

\begin{tabular}{|c|c|c|c|c|}
\hline Variable & $\begin{array}{c}\text { All } \\
(\mathrm{N}=197)\end{array}$ & $\begin{array}{c}\text { AVR } \\
(n=148)\end{array}$ & $\begin{array}{c}\text { MVR } \\
(n=36)\end{array}$ & $\begin{array}{c}\text { DVR } \\
(\mathrm{n}=13)\end{array}$ \\
\hline \multicolumn{5}{|l|}{ Baseline characteristic } \\
\hline Age (y) & $66.9 \pm 4.9$ & $67.7 \pm 5.1$ & $65.2 \pm 3.7$ & $63.3 \pm 2.3$ \\
\hline Female sex & $80(40.6)$ & $54(36.5)$ & $18(50)$ & $8(61.5)$ \\
\hline BMI & $23.1 \pm 3.5$ & $23.2 \pm 3.7$ & $23.3 \pm 3.0$ & $22.0 \pm 2.8$ \\
\hline \multicolumn{5}{|l|}{ NYHA functional class } \\
\hline II & $51(25.9)$ & $36(24.3)$ & $13(36.1)$ & $2(15.4)$ \\
\hline III & $144(73.1)$ & $111(75.0)$ & $22(61.1)$ & $11(84.6)$ \\
\hline IV & $2(1.0)$ & $1(0.7)$ & $1(2.8)$ & $0(0)$ \\
\hline Systemic hypertension & $74(37.6)$ & $62(41.9)$ & $11(30.6)$ & $1(7.7)$ \\
\hline Coronary artery disease & $8(4.1)$ & $7(4.7)$ & $1(2.8)$ & $0(0)$ \\
\hline COPD & $29(14.7)$ & $26(17.6)$ & $2(5.6)$ & $1(7.7)$ \\
\hline Diabetes mellitus & $9(4.6)$ & $6(4.1)$ & $2(5.6)$ & $1(7.7)$ \\
\hline STS predicted risk of mortality $(\%)$ & $1.6 \pm 1.1$ & $1.6 \pm 1.1$ & $1.7 \pm 0.9$ & $1.5 \pm 0.6$ \\
\hline STS predicted risk of morbidity or mortality ( $\%)$ & $12.9 \pm 5.5$ & $12.5 \pm 5.4$ & $14.3 \pm 6.0$ & $13.1 \pm 4.8$ \\
\hline Logistic EuroSCORE II $(\%)$ & $2.8 \pm 2.3$ & $3.0 \pm 2.5$ & $2.5 \pm 1.5$ & $2.2 \pm 1.2$ \\
\hline \multicolumn{5}{|l|}{ Operative details } \\
\hline $\mathrm{CPB}$ time (min) & $102.8 \pm 30.9$ & $99.0 \pm 31.4$ & $102.9 \pm 16.5$ & $145.9 \pm 23.8$ \\
\hline Crossclamp time (min) & $70.2 \pm 26.2$ & $67.9 \pm 26.0$ & $64.5 \pm 14.2$ & $112.8 \pm 14.3$ \\
\hline \multicolumn{5}{|l|}{ Surgical approach } \\
\hline Median sternotomy & $194(98.5)$ & $145(98.0)$ & $36(100)$ & $13(100)$ \\
\hline Minimal sternotomy & $3(1.5)$ & $3(2.0)$ & $0(0)$ & $0(0)$ \\
\hline \multicolumn{5}{|l|}{ Primary outcomes } \\
\hline Valve-related complications* & $1(0.5)$ & $0(0)$ & $1(2.8)$ & $0(0)$ \\
\hline Valve-related complications $\dagger$ & $1(0.5)$ & $0(0)$ & $1(2.9)$ & $0(0)$ \\
\hline
\end{tabular}


TABLE 4. Intraoperative data $(\mathbf{N}=197)$

\begin{tabular}{lc}
\hline \multicolumn{1}{c}{ Parameter } & Result \\
\hline CPB time (min) & $102.8 \pm 30.9$ \\
Crossclamp time (min) & $70.2 \pm 26.2$ \\
Surgical approach & \\
Full sternotomy & $194(98.5)$ \\
Upper hemisternotomy & $3(1.5)$ \\
Operation & \\
AVR & $148(75.1)$ \\
MVR & $36(18.3)$ \\
DVR & $13(6.6)$ \\
Aortic valve size (mm) & 161 \\
19 & $21(13.0)$ \\
21 & $40(24.8)$ \\
23 & $66(41.0)$ \\
25 & $34(21.1)$ \\
Mitral valve size (mm) & 49 \\
25 & $12(24.5)$ \\
27 & $34(69.4)$ \\
29 & $3(6.1)$ \\
Concomitant procedures & \\
Tricuspid valve repair & $54(27.4)$ \\
Atrial fibrillation ablation & $32(16.2)$ \\
Mitral valve repair & $22(11.2)$ \\
Ascending aortoplasty & $16(8.1)$ \\
Bentall procedure & $16(8.1)$ \\
LVOT myectomy & $2(1.0)$ \\
ASD repair & $1(0.5)$ \\
VSD repair & $1(0.5)$ \\
\hline
\end{tabular}

Values are presented as mean \pm standard deviation or $\mathrm{n}(\%) . C P B$, Cardiopulmonary bypass; $A V R$, aortic valve replacement; $M V R$, mitral valve replacement; $D V R$, double valve (aortic and mitral valve) replacement; $L V O T$, left ventricular outflow trace; $A S D$, atrial septal defect; $V S D$, ventricular septal defect.

$P<.001)$, which was consistent with the results in full analysis set (Table 3 and Table 5).

\section{Secondary Outcomes}

All-cause mortality was $3.6 \%$ and these deaths occurred in AVR group (Figure 3). The causes of deaths were reported as heart failure $(\mathrm{n}=1)$, malignant arrhythmia $(\mathrm{n}=1)$, aortic dissection $(\mathrm{n}=1)$, sepsis $(\mathrm{n}=1)$, stroke $(\mathrm{n}=1)$, and unknown reasons $(\mathrm{n}=2)$. No structural valve deterioration and no valve-related reoperation occurred.

Hemodynamic performances classified by valve position and size over time were detailed in Tables 7 and 8 . The peak flow velocity, mean gradient, and EOA for

TABLE 5. Primary outcomes

\begin{tabular}{cccc}
\hline Primary outcomes & n (\%) & $\mathbf{9 5 \%}$ CI (\%) & $\boldsymbol{P}$ value* \\
\hline Valve-related complications $\dagger$ & $1(0.5)$ & $0.1-3.7$ & $<.001$ \\
Valve-related complications $\ddagger$ & $1(0.5)$ & $0.1-3.7$ & $<.001$ \\
\hline
\end{tabular}

CI, Confidence interval. *Compared with pre-set point $9.0 \%$. $\dagger$ Full analysis set. $\ddagger$ Perprotocol set.
TABLE 6. Sensitivity analysis for primary outcomes

\begin{tabular}{lccc}
\hline No. & $\mathbf{n}(\%) \dagger$ & $\begin{array}{c}\mathbf{9 5} \% \\
\mathbf{C I}(\%)\end{array}$ & $\begin{array}{c}\mathbf{9 5} \% \\
\mathbf{C I}(\%)\end{array}$ \\
\hline 0 & $1(0.5)$ & $0.0-1.8$ & $0.0-2.8$ \\
1 & $2(1.0)$ & $0.0-2.7$ & $0.1-3.6$ \\
2 & $3(1.5)$ & $0.0-3.5$ & $0.3-4.4$ \\
3 & $4(2.0)$ & $0.0-4.3$ & $0.6-5.1$ \\
\hline 4 & $5(2.5)$ & $0.1-5.0$ & $0.8-5.8$ \\
\hline 5 & $6(3.0)$ & $0.4-5.7$ & $1.1-6.5$ \\
6 & $7(3.6)$ & $0.7-6.4$ & $1.4-7.2$ \\
7 & $8(4.1)$ & $1.1-7.1$ & $1.8-7.8$ \\
\hline 8 & $9(4.6)$ & $1.4-7.7$ & $2.1-8.5$ \\
\hline
\end{tabular}

CI, Confidence interval. *Number of missing primary end point assessments considered as valve-related complications. †Valve-related complications. $\ddagger$ Asymptotic normal procedure. §Fisher exact test.

implanted aortic bioprostheses of all sizes at 1 month postoperatively were $2.3 \pm 0.4 \mathrm{~m} / \mathrm{s}, 11.6 \pm 3.5 \mathrm{~mm} \mathrm{Hg}$, and $2.0 \pm 0.3 \mathrm{~cm}^{2}$, respectively. These values were maintained through 1 year as the corresponding values were $2.5 \pm 0.4 \mathrm{~m} / \mathrm{s}, 12.8 \pm 4.4 \mathrm{~mm} \mathrm{Hg}$, and $1.9 \pm 0.3 \mathrm{~cm}^{2}$, respectively. Especially for $19 \mathrm{~mm}$ and $21 \mathrm{~mm}$ sizes, the mean gradients and EOA at 1 year were $17.0 \pm 3.8 \mathrm{~mm}$ $\mathrm{Hg}$ and $13.1 \pm 4.0 \mathrm{~mm} \mathrm{Hg}, 1.6 \pm 0.2 \mathrm{~cm}^{2}$ and $1.8 \pm 0.1 \mathrm{~cm}^{2}$, respectively. The mean indexed EOA at 1 month were $1.2 \pm 0.2 \mathrm{~cm}^{2} / \mathrm{m}^{2}, 1.1 \pm 0.2 \mathrm{~cm}^{2} / \mathrm{m}^{2}$, $1.1 \pm 0.1 \mathrm{~cm}^{2} / \mathrm{m}^{2}, \quad 1.3 \pm 0.2 \mathrm{~cm}^{2} / \mathrm{m}^{2}$, and $1.3 \pm 0.2 \mathrm{~cm}^{2} / \mathrm{m}^{2}$ for all sizes, $19 \mathrm{~mm}, 21 \mathrm{~mm}, 23 \mathrm{~mm}$, and $25 \mathrm{~mm}$, respectively. Patient-prosthesis mismatch for AVR, as defined by indexed EOA $<0.85 \mathrm{~cm}^{2} / \mathrm{m}^{2}$, was only $1.3 \%$ ( 2 out of 157 ) in our cohort. Two patients implanted with $19 \mathrm{~mm}$ aortic valves had moderate PPM (the indexed EOA was 0.83 and 0.84, respectively). Hemodynamic performance was also favorable for the mitral bioprostheses. Consistently, postoperative reverse cardiac remodeling was significant as supported by the echocardiographic data (Tables 9 and 10). The percentage of patients with NYHA functional class III and IV decreased from $74.1 \%$ before surgery to $9.3 \%$ at 1 month and $0.5 \%$ at 1 year after surgery (Figure 4 ).

\section{DISCUSSION}

The Cingular bovine pericardial valve was built on the Carpentier-Edwards Perimount valve and incorporated certain innovations. This prospective multicenter clinical trial was set up in China to investigate the safety and effectiveness of the current study valve in a total of 197 patients (Figure 5 and Video 1). We found that the overall rate of valve-related complications was only $0.5 \%$ for surgical AVR and MVR during 1-year follow-up. The 1-year 

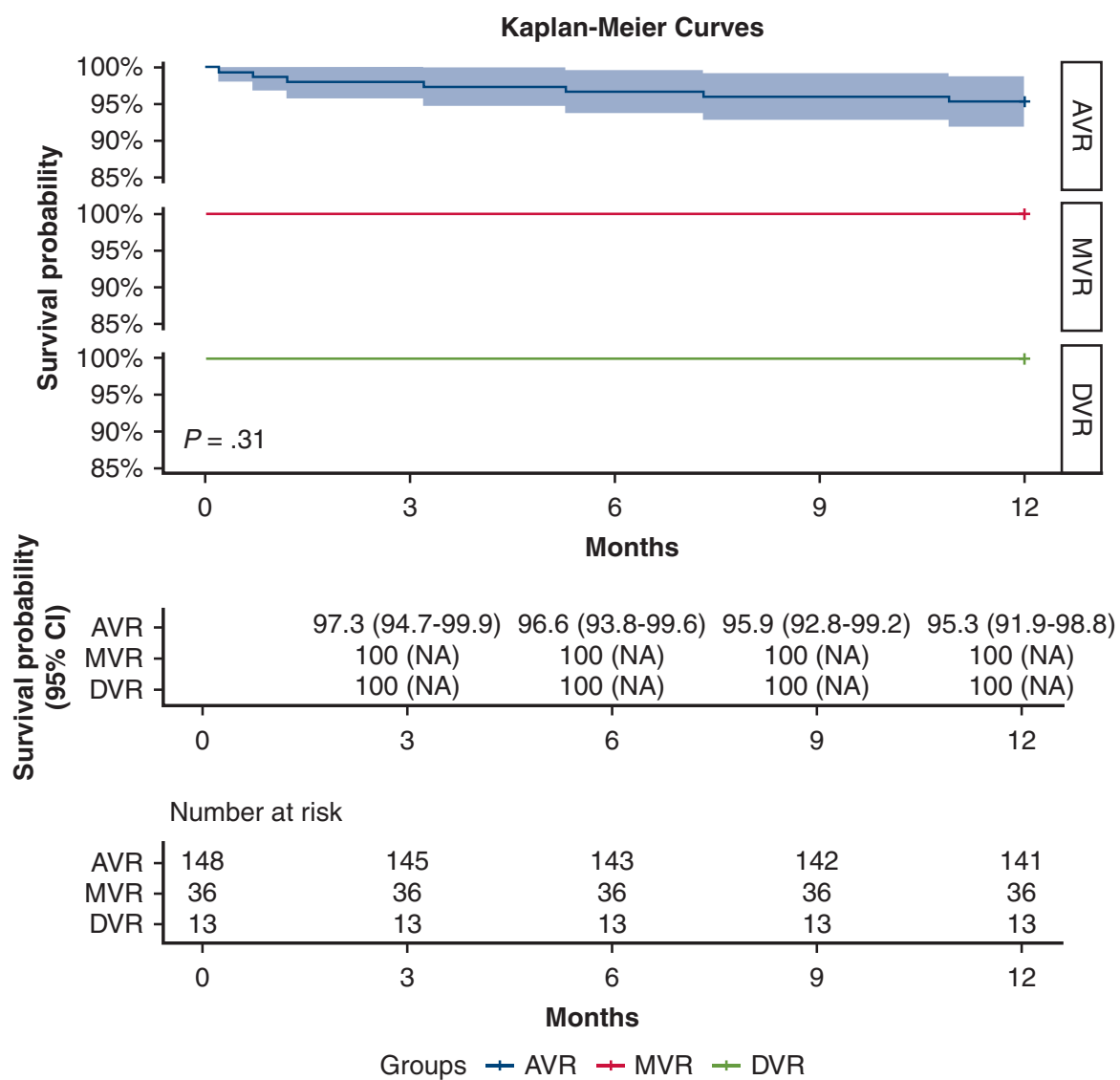

FIGURE 3. Kaplan-Meier curves for survival after the Cingular bovine pericardial valve (Shanghai Cingular Biotech Corporation, Shanghai, China) implantations according to different surgical types. $A V R$, Aortic valve replacement; $M V R$, mitral valve replacement; $D V R$, double valve (aortic and mitral valve) replacement; $C I$, confidence interval; $N A$, not applicable.

outcomes demonstrated that the Cingular bovine pericardial valve is safe and effective.

With an increasing aging population in China and globally, a growing need for bovine pericardial valves is expected. Many commercially available valve substitutes have undergone design modifications over the years, including the well-established Carpentier-Edwards Perimount valve. ${ }^{17,18}$ The Cingular bovine pericardial valve is a trileaflet bioprosthesis. The design concept of the current valve is based on the Carpentier-Edwards Perimount valve and incorporates certain innovations. Mainly, the novel 3- layer design of the stent intends its structure to remain annular both in stationary and stressed states. The 3-layer stent also provides a groove for the alloy wire, ensuring perfect matching between the stent and the alloy wire, thereby avoiding the malposition of the stent and the alloy wire. The malposition often leads to a shift of the alloy wire from the stent which would cause decreased stability of the entire bioprosthesis and uneven stress on the tissue leaflets resulting in wrinkles and expediting wear of the tissue leaflets. Thus, above optimizations would increase the bioprosthetic stability and decrease the possibility and the extent of

TABLE 7. Hemodynamic performance in aortic valve position

\begin{tabular}{|c|c|c|c|c|c|c|}
\hline Time & Parameter & All sizes & $19 \mathrm{~mm}$ & $21 \mathrm{~mm}$ & $23 \mathrm{~mm}$ & $25 \mathrm{~mm}$ \\
\hline \multirow[t]{4}{*}{$1 \mathrm{mo}$} & $\mathrm{PFV}(\mathrm{cm} / \mathrm{s})$ & $2.3 \pm 0.4(\mathrm{n}=157)$ & $2.7 \pm 0.3(\mathrm{n}=20)$ & $2.4 \pm 0.4(\mathrm{n}=40)$ & $2.3 \pm 0.3(\mathrm{n}=64)$ & $2.1 \pm 0.3(\mathrm{n}=33)$ \\
\hline & MG (mm Hg) & $11.6 \pm 3.5$ & $15.2 \pm 3.4$ & $12.1 \pm 3.7$ & $11.2 \pm 2.8$ & $9.3 \pm 2.8$ \\
\hline & $\operatorname{EOA}\left(\mathrm{cm}^{2}\right)$ & $2.0 \pm 0.3$ & $1.7 \pm 0.2$ & $1.8 \pm 0.1$ & $2.1 \pm 0.2$ & $2.3 \pm 0.2$ \\
\hline & $\operatorname{iEOA}\left(\mathrm{cm}^{2} / \mathrm{m}^{2}\right)$ & $1.2 \pm 0.2$ & $1.1 \pm 0.2$ & $1.1 \pm 0.1$ & $1.3 \pm 0.2$ & $1.3 \pm 0.2$ \\
\hline \multirow[t]{3}{*}{$1 \mathrm{y}$} & $\mathrm{PFV}(\mathrm{cm} / \mathrm{s})$ & $2.5 \pm 0.4(\mathrm{n}=151)$ & $2.8 \pm 0.4(\mathrm{n}=19)$ & $2.5 \pm 0.4(\mathrm{n}=39)$ & $2.4 \pm 0.3(\mathrm{n}=61)$ & $2.2 \pm 0.3(\mathrm{n}=32)$ \\
\hline & $\mathrm{MG}(\mathrm{mm} \mathrm{Hg})$ & $12.8 \pm 4.4$ & $17.0 \pm 3.8$ & $13.1 \pm 4.0$ & $12.7 \pm 4.4$ & $10.0 \pm 2.9$ \\
\hline & $\mathrm{EOA}\left(\mathrm{cm}^{2}\right)$ & $1.9 \pm 0.3$ & $1.6 \pm 0.2$ & $1.8 \pm 0.1$ & $1.9 \pm 0.2$ & $2.2 \pm 0.2$ \\
\hline
\end{tabular}

Values are presented as mean \pm standard deviation. $P F V$, Peak flow velocity; $M G$, mean gradient; $E O A$, effective orifice area; $i E O A$, indexed effective orifice area. 
TABLE 8. Hemodynamic performance in mitral valve position

\begin{tabular}{|c|c|c|c|c|c|}
\hline Time & Parameter & All sizes & $25 \mathrm{~mm}$ & $27 \mathrm{~mm}$ & $29 \mathrm{~mm}$ \\
\hline \multirow[t]{3}{*}{$1 \mathrm{mo}$} & PHT (ms) & $105.2 \pm 23.4(n=48)$ & $105.7 \pm 19.6(n=12)$ & $103.7 \pm 25.0(\mathrm{n}=33)$ & $119.7 \pm 20.6(\mathrm{n}=3)$ \\
\hline & MG (mm Hg) & $4.2 \pm 1.3$ & $3.8 \pm 1.5$ & $4.4 \pm 1.3$ & $3.7 \pm 0.4$ \\
\hline & $\operatorname{EOA}\left(\mathrm{cm}^{2}\right)$ & $2.3 \pm 0.4$ & $2.2 \pm 0.3$ & $2.4 \pm 0.4$ & $2.3 \pm 0.2$ \\
\hline \multirow[t]{3}{*}{$1-y$} & PHT (ms) & $111.0 \pm 24.4(n=49)$ & $112.1 \pm 16.5(n=12)$ & $108.6 \pm 25.4(\mathrm{n}=34)$ & $133.0 \pm 35.5(\mathrm{n}=3)$ \\
\hline & $\mathrm{MG}(\mathrm{mm} \mathrm{Hg})$ & $4.3 \pm 2.0$ & $4.3 \pm 1.6$ & $4.4 \pm 2.2$ & $3.2 \pm 0.6$ \\
\hline & $\operatorname{EOA}\left(\mathrm{cm}^{2}\right)$ & $2.1 \pm 0.3$ & $2.1 \pm 0.4$ & $2.1 \pm 0.3$ & $2.1 \pm 0.4$ \\
\hline
\end{tabular}

Values are presented as mean \pm standard deviation. $P H T$, Pressure half time; $M G$, mean gradient; $E O A$, effective orifice area.

TABLE 9. Preoperative and postoperative transthoracic echocardiographic findings

\begin{tabular}{|c|c|c|c|}
\hline Parameter & Preoperative & $1 \mathrm{mo}$ & $1 \mathbf{y}$ \\
\hline \multicolumn{4}{|l|}{ Total } \\
\hline LVEF (\%) & $59.3 \pm 10.0$ & $62.3 \pm 8.6$ & $65.7 \pm 8.8$ \\
\hline $\mathrm{LAD}(\mathrm{mm})$ & $45.2 \pm 8.8$ & $41.3 \pm 7.6$ & $42.1 \pm 7.3$ \\
\hline RAD (mm) & $51.0 \pm 8.5$ & $47.8 \pm 6.2$ & $48.6 \pm 6.1$ \\
\hline LVESD (mm) & $36.6 \pm 9.5$ & $30.5 \pm 6.8$ & $28.6 \pm 6.2$ \\
\hline LVEDD (mm) & $53.9 \pm 9.6$ & $45.9 \pm 6.8$ & $44.6 \pm 5.9$ \\
\hline RVEDD-basal (mm) & $31.7 \pm 5.4$ & $31.8 \pm 4.2$ & $33.3 \pm 4.2$ \\
\hline RVEDD-mid (mm) & $19.6 \pm 4.3$ & $19.7 \pm 3.6$ & $21.0 \pm 3.4$ \\
\hline LVPW (mm) & $11.1 \pm 1.7$ & $11.1 \pm 1.6$ & $10.8 \pm 1.4$ \\
\hline IVS (mm) & $11.8 \pm 2.2$ & $11.9 \pm 2.0$ & $11.7 \pm 1.9$ \\
\hline LVMI* $\left(g / m^{2}\right)$ & $184.6 \pm 63.3$ & $140.5 \pm 41.5$ & $128.8 \pm 33.1$ \\
\hline \multicolumn{4}{|l|}{ AVR group } \\
\hline LVEF (\%) & $58.4 \pm 10.2$ & $61.8 \pm 8.6$ & $65.8 \pm 8.0$ \\
\hline $\mathrm{LAD}(\mathrm{mm})$ & $42.7 \pm 6.4$ & $39.2 \pm 5.4$ & $40.1 \pm 4.7$ \\
\hline $\operatorname{RAD}(\mathrm{mm})$ & $49.2 \pm 6.9$ & $47.4 \pm 5.7$ & $48.5 \pm 5.1$ \\
\hline LVESD (mm) & $37.6 \pm 9.6$ & $30.7 \pm 6.9$ & $28.3 \pm 5.7$ \\
\hline LVEDD (mm) & $54.7 \pm 9.8$ & $45.9 \pm 7.1$ & $44.3 \pm 5.7$ \\
\hline RVEDD-basal (mm) & $31.3 \pm 5.4$ & $31.9 \pm 4.2$ & $33.4 \pm 4.3$ \\
\hline RVEDD-mid (mm) & $19.4 \pm 4.3$ & $19.7 \pm 3.4$ & $21.0 \pm 3.2$ \\
\hline LVPW (mm) & $11.5 \pm 1.7$ & $11.4 \pm 1.6$ & $11.0 \pm 1.4$ \\
\hline IVS (mm) & $12.3 \pm 2.0$ & $12.3 \pm 2.0$ & $11.9 \pm 1.9$ \\
\hline LVMI* $\left(\mathrm{g} / \mathrm{m}^{2}\right)$ & $196.4 \pm 61.9$ & $145.5 \pm 42.0$ & $130.0 \pm 33.3$ \\
\hline \multicolumn{4}{|l|}{ MVR group } \\
\hline LVEF (\%) & $63.5 \pm 9.0$ & $65.2 \pm 7.6$ & $65.3 \pm 12.3$ \\
\hline LAD (mm) & $53.2 \pm 11.3$ & $48.2 \pm 10.0$ & $49.1 \pm 10.6$ \\
\hline RAD (mm) & $56.3 \pm 11.7$ & $48.9 \pm 8.1$ & $49.8 \pm 9.0$ \\
\hline LVESD (mm) & $32.4 \pm 7.6$ & $29.3 \pm 6.5$ & $29.8 \pm 8.0$ \\
\hline LVEDD (mm) & $50.6 \pm 7.6$ & $46.0 \pm 6.4$ & $46.1 \pm 6.6$ \\
\hline RVEDD-basal (mm) & $32.7 \pm 5.2$ & $31.0 \pm 3.8$ & $32.9 \pm 3.9$ \\
\hline RVEDD-mid (mm) & $20.3 \pm 4.5$ & $20.1 \pm 4.2$ & $20.3 \pm 3.6$ \\
\hline LVPW (mm) & $9.7 \pm 0.9$ & $9.9 \pm 0.8$ & $10.3 \pm 1.1$ \\
\hline IVS (mm) & $10.1 \pm 1.9$ & $10.4 \pm 1.1$ & $10.9 \pm 1.3$ \\
\hline LVMI* $\left(\mathrm{g} / \mathrm{m}^{2}\right)$ & $136.0 \pm 42.7$ & $118.7 \pm 31.8$ & $125.5 \pm 30.4$ \\
\hline \multicolumn{4}{|l|}{ DVR group } \\
\hline $\operatorname{LVEF}(\%)$ & $57.7 \pm 8.6$ & $59.8 \pm 10.5$ & $65.4 \pm 4.7$ \\
\hline LAD (mm) & $51.7 \pm 8.9$ & $45.9 \pm 8.4$ & $43.6 \pm 7.0$ \\
\hline RAD (mm) & $56.5 \pm 7.5$ & $49.2 \pm 6.1$ & $46.2 \pm 5.1$ \\
\hline LVESD (mm) & $37.2 \pm 10.8$ & $31.9 \pm 6.5$ & $27.8 \pm 5.5$ \\
\hline LVEDD (mm) & $53.6 \pm 11.4$ & $46.3 \pm 4.6$ & $43.8 \pm 6.9$ \\
\hline RVEDD-basal (mm) & $33.6 \pm 5.7$ & $31.8 \pm 4.2$ & $33.2 \pm 4.1$ \\
\hline RVEDD-mid (mm) & $19.9 \pm 2.7$ & $18.8 \pm 3.2$ & $21.9 \pm 4.5$ \\
\hline LVPW (mm) & $10.8 \pm 1.1$ & $10.9 \pm 1.6$ & $10.3 \pm 1.1$ \\
\hline IVS (mm) & $11.9 \pm 2.7$ & $11.8 \pm 2.3$ & $11.8 \pm 2.4$ \\
\hline LVMI* $\left(\mathrm{g} / \mathrm{m}^{2}\right)$ & $185.4 \pm 66.0$ & $144.3 \pm 42.8$ & $125.6 \pm 38.9$ \\
\hline
\end{tabular}

Values are presented as mean \pm standard deviation. $L V E F$, Left ventricular ejection fraction; $L A D$, left atrial diameter; $R A D$, right atrial diameter; $L V E S D$, left ventricular endsystolic diameter; $L V E D D$, left ventricular end-diastolic diameter; $R V E D D$, right ventricular end-diastolic diameter; $L V P W$, diastolic left ventricular posterior wall thickness; IVS, diastolic interventricular septum thickness; $L V M I$, left ventricular mass index; $A V R$, aortic valve replacement; $M V R$, mitral valve replacement; $D V R$, double valve (aortic and mitral valve) replacement. ${ }^{\mathrm{L} V M I}=\mathrm{LV}$ mass/BSA; $\mathrm{LV}$ mass $(\mathrm{g})=1.04\left[(\mathrm{LVEDD}+\mathrm{LVPW}+\mathrm{IVS})^{3}-\mathrm{LVEDD}^{3}\right]-13.6$. 
TABLE 10. Longitudinal analysis with linear mixed effects models for postoperative echocardiographic findings

\begin{tabular}{|c|c|c|c|c|c|c|}
\hline \multirow[b]{2}{*}{ Parameter } & \multicolumn{3}{|c|}{$1 \mathrm{mo}^{*}$} & \multicolumn{3}{|c|}{$1 y^{*}$} \\
\hline & $\overline{\text { Estimate } \dagger}$ & $95 \% \mathrm{CI}$ & $P$ value & $\overline{\text { Estimate }} \dagger$ & $95 \% \mathrm{CI}$ & $P$ value \\
\hline \multicolumn{7}{|l|}{ Total } \\
\hline LVEF & 2.90 & $1.52,4.27$ & $<.001$ & 6.26 & $4.88,7.65$ & $<.001$ \\
\hline LAD & -3.91 & $-4.60,-3.22$ & $<.001$ & -3.14 & $-3.84,-2.45$ & $<.001$ \\
\hline RAD & -3.21 & $-4.14,-2.27$ & $<.001$ & -2.33 & $-3.28,-1.39$ & $<.001$ \\
\hline LVESD & -5.94 & $-6.85,-5.03$ & $<.001$ & -7.85 & $-8.77,-6.93$ & $<.001$ \\
\hline LVEDD & -7.90 & $-8.85,-6.95$ & $<.001$ & -9.11 & $-10.07,-8.16$ & $<.001$ \\
\hline RVEDD-basal & 0.00 & $-0.71,0.71$ & .994 & 1.62 & $0.90,2.33$ & $<.001$ \\
\hline RVEDD-mid & 0.07 & $-0.56,0.69$ & .834 & 1.34 & $0.71,1.97$ & $<.001$ \\
\hline LVPW & 0.05 & $-0.16,0.26$ & .636 & -0.25 & $-0.46,-0.04$ & .020 \\
\hline IVS & 0.06 & $-0.18,0.31$ & 620 & -0.16 & $-0.41,0.08$ & .192 \\
\hline $\mathrm{LVMI}^{\dagger}$ & -43.20 & $-49.17,-37.23$ & $<.001$ & -54.52 & $-60.55,-48.50$ & $<.001$ \\
\hline \multicolumn{7}{|l|}{ AVR group } \\
\hline LVEF & 3.35 & $1.77,4.93$ & $<.001$ & 7.27 & $5.66,8.87$ & $<.001$ \\
\hline LAD & -3.47 & $-4.25,-2.69$ & $<.001$ & -2.47 & $-3.26,-1.67$ & $<.001$ \\
\hline RAD & -1.84 & $-2.82,-0.87$ & $<.001$ & -0.55 & $-1.54,0.44$ & .278 \\
\hline LVESD & -6.77 & $-7.82,-5.72$ & $<.001$ & -9.06 & $-10.13,-8.00$ & $<.001$ \\
\hline LVEDD & -8.78 & $-9.89,-7.68$ & $<.001$ & -10.20 & $-11.32,-9.08$ & $<.001$ \\
\hline RVEDD-basal & 0.56 & $-0.28,1.40$ & .189 & 2.15 & $1.30,3.00$ & $<.001$ \\
\hline RVEDD-mid & 0.24 & $-0.49,0.97$ & .515 & 1.62 & $0.88,2.36$ & $<.001$ \\
\hline LVPW & -0.02 & $-0.27,0.23$ & .894 & -0.45 & $-0.71,-0.20$ & .001 \\
\hline IVS & 0.02 & $-0.26,0.29$ & .913 & -0.39 & $-0.67,-0.11$ & .007 \\
\hline $\mathrm{LVMI}_{\ddagger}$ & -50.12 & $-56.89,-43.36$ & $<.001$ & -65.19 & $-72.06,-58.33$ & $<.001$ \\
\hline \multicolumn{7}{|l|}{ MVR group } \\
\hline LVEF & 1.38 & $-2.00,4.76$ & .418 & 1.79 & $-1.55,5.14$ & .289 \\
\hline LAD & -5.04 & $-6.69,-3.40$ & $<.001$ & -4.11 & $-5.74,-2.48$ & $<.001$ \\
\hline RAD & -7.22 & $-9.63,-4.80$ & $<.001$ & -6.56 & $-8.95,-4.16$ & $<.001$ \\
\hline LVESD & -2.81 & $-4.69,-0.93$ & .004 & -2.53 & $-4.39,-0.67$ & .008 \\
\hline LVEDD & -4.53 & $-6.43,-2.63$ & $<.001$ & -4.58 & $-6.47,-2.70$ & $<.001$ \\
\hline RVEDD-basal & -1.62 & $-3.02,-0.22$ & .024 & 0.22 & $-1.17,1.61$ & .750 \\
\hline RVEDD-mid & -0.20 & $-1.64,1.24$ & .783 & 0.03 & $-1.40,1.45$ & .969 \\
\hline LVPW & 0.27 & $-0.10,0.64$ & .150 & 0.64 & $0.27,1.00$ & .001 \\
\hline IVS & 0.30 & $-0.32,0.93$ & .337 & 0.72 & $0.10,1.34$ & .024 \\
\hline $\mathrm{LVMI}^{\dagger}$ & -16.05 & $-27.43,-4.67$ & .006 & -10.49 & $-21.76,0.78$ & .068 \\
\hline \multicolumn{7}{|l|}{ DVR group } \\
\hline LVEF & 2.08 & $-2.14,6.29$ & .319 & 7.74 & $3.53,11.95$ & .001 \\
\hline LAD & -5.77 & $-8.31,-3.23$ & $<.001$ & -8.08 & $-10.62,-5.54$ & $<.001$ \\
\hline RAD & -7.31 & $-10.68,-3.94$ & .000 & -10.31 & $-13.68,-6.94$ & $<.001$ \\
\hline LVESD & -5.31 & $-8.25,-2.37$ & .001 & -9.38 & $-12.32,-6.45$ & $<.001$ \\
\hline LVEDD & -7.31 & $-10.74,-3.88$ & .000 & -9.85 & $-13.28,-6.42$ & $<.001$ \\
\hline RVEDD-basal & -1.77 & $-4.66,1.12$ & .219 & -0.38 & $-3.28,2.51$ & .786 \\
\hline RVEDD-mid & -1.08 & $-3.46,1.30$ & .360 & 2.00 & $-0.38,4.38$ & .096 \\
\hline LVPW & 0.15 & $-0.52,0.83$ & .642 & -0.46 & $-1.14,0.21$ & .171 \\
\hline IVS & -0.15 & $-0.97,0.66$ & .701 & -0.15 & $-0.97,0.66$ & .701 \\
\hline $\mathrm{LVMI}^{\dagger}$ & -41.12 & $-59.75,-22.49$ & $<.001$ & -59.75 & $-78.38,-41.12$ & $<.001$ \\
\hline
\end{tabular}

$C I$, Confidence interval; $L V E F$, left ventricular ejection fraction; $L A D$, left atrial diameter; $R A D$, right atrial diameter; $L V E S D$, left ventricular end-systolic diameter; $L V E D D$, left ventricular end-diastolic diameter; RVEDD, right ventricular end-diastolic diameter; $L V P W$, diastolic left ventricular posterior wall thickness; IVS, diastolic interventricular septum thickness; $L V M I$, left ventricular mass index; $A V R$, aortic valve replacement; $M V R$, mitral valve replacement; $D V R$, double valve (aortic and mitral valve) replacement.

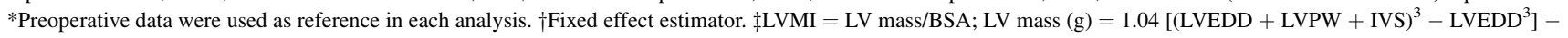
13.6 .

triangular leaflet opening. The redesigned sewing cuff using Reemay (Berry Global, Old Hickory, Tenn) with double velour Dacron (BRAD, Tempe, Ariz) was used in this valve. Based on the results of this trial, the current valve is safe for AVR and MVR because the incidence of valve-related complications was very low during 1 -year follow-up. The durability will be validated by the long-term follow-up. The surgical nuances of implanting this valve seemed not 


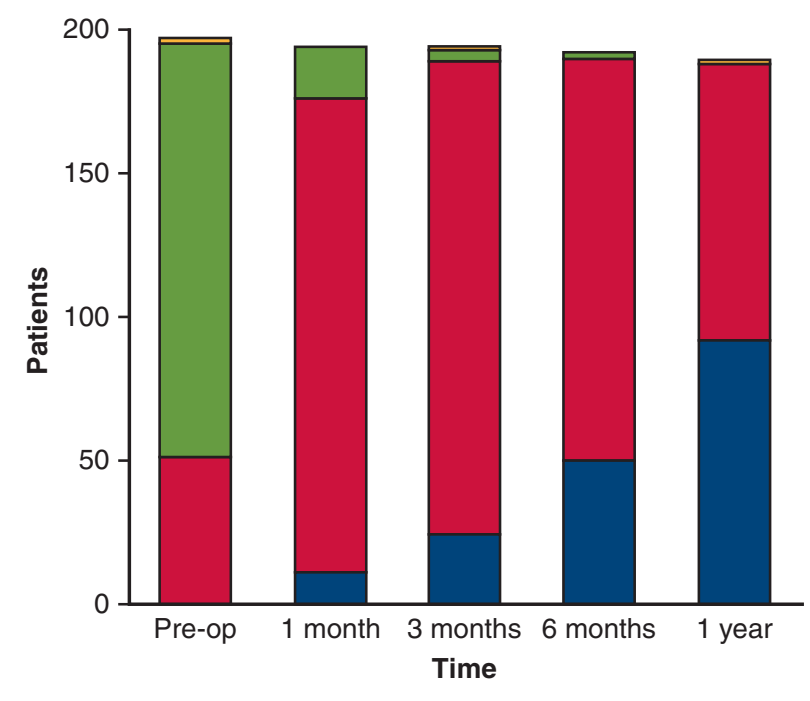

$\square$ Class I $\square$ Class II $\square$ Class III $\square$ Class IV

FIGURE 4. Improvement of New York Heart Association functional class in patients receiving Cingular bovine pericardial valve (Shanghai Cingular Biotech Corporation, Shanghai, China) implantations during 1-year follow-up compared with preoperative status.

significantly different from other available bioprosthetic valves based on the feedbacks from the surgeons involved in this trial.

The development of stented tissue valves with improved hemodynamic performance is an important goal in the field of cardiac surgery. Cohen and colleagues ${ }^{8}$ reported the EOA and mean gradient of $1.9 \pm 0.6 \mathrm{~cm}^{2}$ and $7.1 \pm 3.7 \mathrm{~mm} \mathrm{Hg}$ at 1 year for Carpentier-Edwards Perimount aortic bioprosthesis. Similarly, Dalmau and colleagues ${ }^{9}$ reported the EOA and mean gradient of $1.9 \pm 0.4 \mathrm{~cm}^{2}$ and $10.3 \pm 3.4 \mathrm{~mm} \mathrm{Hg}$ at 1 year for Carpentier-Edwards Perimount Magna valve. However, the percentage of $19 \mathrm{~mm}$ size was low in these 2 cohorts. Nishioka and colleagues ${ }^{19}$ reported that the EOA were $1.3 \pm 0.2 \mathrm{~cm}^{2}, 1.3 \pm 0.2 \mathrm{~cm}^{2}$, and $1.3 \pm 0.2 \mathrm{~cm}^{2}$ for $19-\mathrm{mm}$ valve size and $1.5 \pm 0.3 \mathrm{~cm}^{2}, 1.6 \pm 0.2 \mathrm{~cm}^{2}$, and $1.4 \pm 0.3 \mathrm{~cm}^{2}$ for $21-$ $\mathrm{mm}$ valve size of Carpentier-Edwards Perimount valve, Magna and Magna Ease at least 6 months in Japanese elderly patients, respectively. The Prospective, Nonrandomized, Multicenter Clinical Evaluation of Edwards Pericardial Bioprostheses With a New Tissue Treatment Platform (COMMENCE) trial showed the EOAs and mean gradients were $1.1 \pm 0.2 \mathrm{~cm}^{2}$ and $1.3 \pm 0.3 \mathrm{~cm}^{2}, 17.6 \pm 7.8 \mathrm{~mm} \mathrm{Hg}$, and $12.6 \pm 4.7 \mathrm{~mm} \mathrm{Hg}$ for $19-\mathrm{mm}$ and 21-mm sizes of Carpentier-Edwards Perimount Magna Ease with Resilia tissue at 1 year, respectively. ${ }^{20}$

The excellent hemodynamic results of the Cingular bovine pericardial valve were comparable to the wellestablished valves, even better in the small size aortic valves (19 $\mathrm{mm}$ and $21 \mathrm{~mm}$ ). Generally, the average body size of
Chinese patients is smaller than that of Western patients. As shown in our data, $19-\mathrm{mm}$ and $21-\mathrm{mm}$ size valves were very common in our study. Stented tissue valves have relatively bulky sewing rings and stents that would decrease the EOA and increase the risk of PPM, particularly in patients with small aortic roots. ${ }^{21}$ However, for $19-\mathrm{mm}$ and 21-mm sizes of the Cingular bovine pericardial aortic valve, the EOAs at 1 month were $1.7 \pm 0.2 \mathrm{~cm}^{2}$ and $1.8 \pm 0.1 \mathrm{~cm}^{2}$, respectively. The corresponding indexed EOAs were $1.1 \pm 0.2 \mathrm{~cm}^{2} / \mathrm{m}^{2}$ and $1.1 \pm 0.1 \mathrm{~cm}^{2} / \mathrm{m}^{2}$, respectively. The incidence of PPM in the aortic valve position was very low $(1.3 \%)$ for this valve despite that the percentage of small size aortic valves was high in our study.

The design of the Cingular bovine pericardial mitral valve was basically the same as the Cingular bovine pericardial aortic valve. Consistent with those in the aortic position, the Cingular bioprostheses implanted in the mitral position also exhibited excellent hemodynamic status: at 1 month and 1 year after surgery, the mean transmitral gradients were $<5 \mathrm{~mm} \mathrm{Hg}$ in all subgroups receiving different sizes of prostheses, which compared favorably with other products. ${ }^{22}$ Our data also demonstrated no signs of structural valve deterioration at 1 year. Given that bioprosthetic durability is typically lower in the mitral position because of the higher pressure imposed on the cusps during systole, our trial enrolled MVR patients to validate the universality of this product in both positions. ${ }^{23}$ Nevertheless, longer echocardiography follow-ups are warranted to evaluate and compare prosthetic function, leaflet rigidity and structural integrity between the 2 positions.

The significant improvement of postoperative heart function in our patients demonstrated clinical effectiveness of the study valve. This valve can be used as an alternative for AVR and MVR, especially for patients with small aortic roots. Our results may also be used as contemporary benchmark for other surgical bioprostheses or transcatheter valves.

\section{Limitations}

This trial was a nonrandomized, single-arm study without a concurrent control group. Thus, it was susceptible to selection bias. The current data were the 1-year outcomes and additional follow-up is required to evaluate long-term safety and effectiveness. We plan to follow these patients up to 5 years postoperatively. Moreover, this trial enrolled both AVR and MVR patients and different surgery may contaminate outcomes of the study end points.

\section{CONCLUSIONS}

The Cingular bovine pericardial valve was safe and effective for surgical AVR and MVR. The overall rate of valverelated complications at 1 year after valve implantations was very low. Early hemodynamic performance was 


\section{A prospective, multi-center, single-arm trial for a bovine pericardial valve}

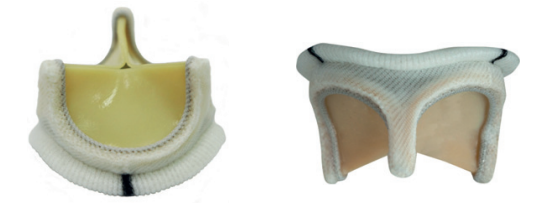

Enrollment $(\mathrm{N}=197)$

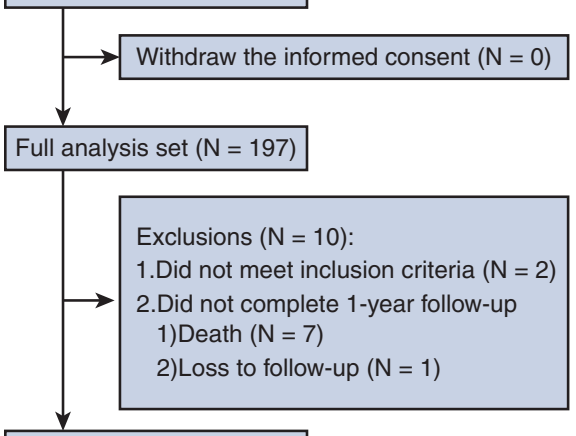

Per-protocol set $(\mathrm{N}=187)$

\begin{tabular}{|cccc|}
\hline Primary outcomes & $\mathrm{N}(\%)$ & $95 \% \mathrm{Cl}$ & $P$ value $^{*}$ \\
\hline Valve-related complications $^{1}$ & $1(0.5 \%)$ & $0.1 \%-3.7 \%$ & $<.001$ \\
\hline Valve-related complications $^{2}$ & $1(0.5 \%)$ & $0.1 \%-3.7 \%$ & $<.001$ \\
\hline
\end{tabular}

$P$ value*: compared with pre-set point $9.0 \%$.

1: full analysis set; 2 : per-protocol set.

\begin{tabular}{l}
\hline Secondary outcomes \\
\hline - The procedural success rate \\
was $100 \%$. \\
- All-cause mortality was $3.6 \%$. \\
- No structural valve \\
deterioration. \\
- No endocarditis. \\
- PPM was only $1.3 \%$ in AVR \\
patients.
\end{tabular}

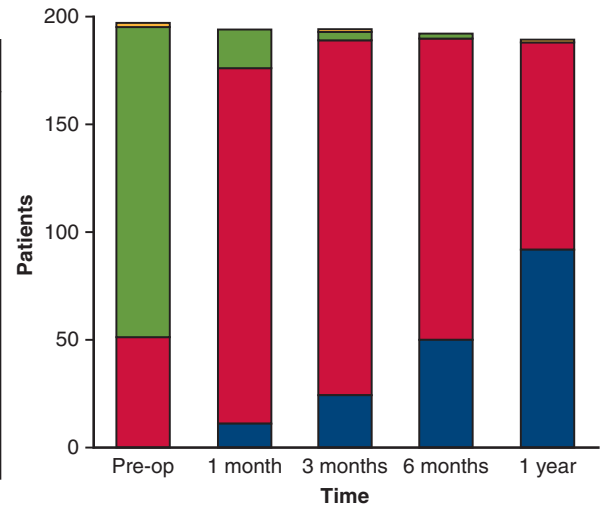

$\square$ Class I $\square$ Class II $\square$ Class III $\square$ Class IV

\section{Conclusion}

- The Cingular bovine pericardial valve was safe and effective for surgical aortic and mitral valve replacement.

- Early hemodynamic performance was excellent even for the small sizes of aortic bioprostheses.

FIGURE 5. A prospective, multicenter, single-arm trial for Cingular bovine pericardial valves (Shanghai Cingular Biotech Corporation, Shanghai, China). This study found that the Cingular bovine pericardial valve was safe and effective for surgical aortic or mitral valve replacement. Early hemodynamic performance was excellent even for the small sizes of aortic bioprostheses. $C I$, Confidence interval; $P P M$, patient-prosthesis mismatch; $A V R$, aortic valve replacement.

excellent even for the small sizes of aortic bioprostheses. Long-term follow-up and a randomized controlled trial are recommended in the future.

\section{Conflict of Interest Statement}

The authors reported no conflicts of interest.
The Journal policy requires editors and reviewers to disclose conflicts of interest and to decline handling or reviewing manuscripts for which they may have a conflict of interest. The editors and reviewers of this article have no conflicts of interest.

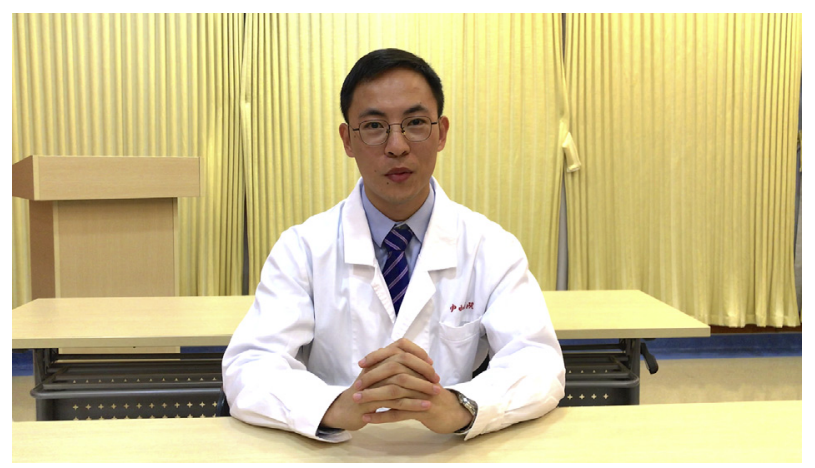

VIDEO 1. Dr Chen introduces the background, method, outcomes, and conclusion of this clinical trial. Video available at: https://www.jtcvs.org/ article/S2666-2736(20)30023-1/fulltext.

\section{References}

1. Banbury MK, Cosgrove DM III, Thomas JD, Blackstone EH, Rajeswaran J, Okies JE, et al. Hemodynamic stability during 17 years of the CarpentierEdwards aortic pericardial bioprosthesis. Ann Thorac Surg. 2002;73:1460-5.

2. Eichinger WB, Botzenhardt F, Keithahn A, Guenzinger R, Bleiziffer S, Wagner I, et al. Exercise hemodynamics of bovine versus porcine bioprostheses: a prospective randomized comparison of the mosaic and perimount aortic valves. $J$ Thorac Cardiovasc Surg. 2005;129:1056-63.

3. McClure RS, Narayanasamy N, Wiegerinck E, Lipsitz S, Maloney A, Byrne JG, et al. Late outcomes for aortic valve replacement with the Carpentier-Edwards pericardial bioprosthesis: up to 17-year follow-up in 1,000 patients. Ann Thorac Surg. 2010;89:1410-6.

4. Forcillo J, Pellerin M, Perrault LP, Cartier R, Bouchard D, Demers P, et al. Carpentier-Edwards pericardial valve in the aortic position: 25-years experience. Ann Thorac Surg. 2013;96:486-93.

5. Bourguignon T, Bouquiaux-Stablo AL, Candolfi P, Mirza A, Loardi C, May MA, et al. Very long-term outcomes of the Carpentier-Edwards Perimount valve in aortic position. Ann Thorac Surg. 2015;99:831-7.

6. Bourguignon T, Lhommet P, El Khoury R, Candolfi P, Loardi C, Mirza A, et al. Very long-term outcomes of the Carpentier-Edwards Perimount aortic valve in patients aged 50-65 years. Eur J Cardiothorac Surg. 2016;49:1462-8. 
7. Borger MA, Nette AF, Maganti M, Feindel CM. Carpentier-Edwards Perimount Magna valve versus Medtronic Hancock II: a matched hemodynamic comparison. Ann Thorac Surg. 2007;83:2054-8.

8. Cohen G, Zagorski B, Christakis GT, Joyner CD, Vincent J, Sever J, et al. Are stentless valves hemodynamically superior to stented valves? Long-term follow-up of a randomized trial comparing Carpentier-Edwards pericardial valve with the Toronto stentless porcine valve. J Thorac Cardiovasc Surg. 2010;139: 848-59.

9. Dalmau MJ, Gonzalez-Santos JM, Blázquez JA, Sastre JA, López-Rodríguez J, Bueno M, et al. Hemodynamic performance of the Medtronic Mosaic and Perimount Magna aortic bioprostheses: five-year results of a prospectively randomized study. Eur J Cardiothorac Surg. 2011;39:844-52.

10. Chen JM, Ding Y, Lu SY, Pan S, Abudupataer M, Hong T, et al. Noninferiority of Shanghai Cingular Biotech's bovine pericardial valve preclinical study in juvenile ovine model. J Thorac Dis. 2016;8:1179-87.

11. Nishimura RA, Otto CM, Bonow RO, Carabello BA, Erwin JP III, Fleisher LA, et al. 2014 AHA/ACC guideline for the management of patients with valvular heart disease: a report of the American College of Cardiology/American Heart Association task force on practice guidelines. J Thorac Cardiovasc Surg. 2014; 148:e1-132.

12. Falk V, Baumgartner H, Bax JJ, De Bonis M, Hamm C, Holm PJ, et al. 2017 ESC/ EACTS guidelines for the management of valvular heart disease. Eur J Cardiothorac Surg. 2017;52:616-64.

13. Wu Y, Butchart EG, Borer JS, Yoganathan A, Grunkemeier GL. Clinical evaluation of new heart valve prostheses: update of objective performance criteria. Ann Thorac Surg. 2014;98:1865-74.

14. Akins CW, Miller DC, Turina MI, Kouchoukos NT, Blackstone EH, Grunkemeier GL, et al. Guidelines for reporting mortality and morbidity after cardiac valve interventions. Eur J Cardiothorac Surg. 2008;33:523-8.

15. Blais C, Dumesnil JG, Baillot R, Simard S, Doyle D, Pibarot P. Impact of valve prosthesis-patient mismatch on short-term mortality after aortic valve replacement. Circulation. 2003;108:983-8.
16. Fuster RG, Montero Argudo JA, Albarova OG, Sos FH, López SC, Codoñer MB, et al. Patient-prosthesis mismatch in aortic valve replacement: really tolerable? Eur J Cardiothorac Surg. 2005;27:441-9.

17. Wendt D, Stuhle S, Piotrowski JA, Wendt H, Thielmann M, Jakob H, et al. Comparison of flow dynamics of Perimount Magna and Magna Ease aortic valve prostheses. Biomed Tech (Berl). 2012;57:97-106.

18. Wyss TR, Bigler M, Stalder M, Englberger L, Aymard T, Kadner A, et al. Absence of prosthesis-patient mismatch with the new generation of Edwards stented aortic bioprosthesis. Interact Cardiovasc Thorac Surg. 2010;10:884-7.

19. Nishioka N, Yamada A, Ujihira K, Iba Y, Maruyama R, Hatta E, et al. Outcomes of surgical aortic valve replacement using Carpentier-Edwards PERIMOUNT bioprosthesis series in elderly patients with severe aortic valve stenosis: a retrospective cohort study. Gen Thorac Cardiovasc Surg. 2016;64:728-34.

20. Puskas JD, Bavaria JE, Svensson LG, Blackstone EH, Griffith B, Gammie JS et al. The COMMENCE trial: 2-year outcomes with an aortic bioprosthesis with RESILIA tissue. Eur J Cardiothorac Surg. 2017;52:432-9.

21. Gonzalez-Juanatey JR, Garcia-Acuna JM, Vega Fernandez M, Amaro Cendón A Castelo Fuentes V, García-Bengoechea JB, et al. Influence of the size of aortic valve prostheses on hemodynamics and change in left ventricular mass: implications for the surgical management of aortic stenosis. J Thorac Cardiovasc Surg. 1996;112:273-80.

22. Blauwet LA, Malouf JF, Connolly HM, Hodge DO, Evans KN, Herges RM, et al. Comprehensive echocardiographic assessment of normal mitral Medtronic Hancock II, Medtronic Mosaic, and Carpentier-Edwards Perimount bioprostheses early after implantation. J Am Soc Echocardiogr. 2010;23:656-66.

23. Valfre C, Ius P, Minniti G, Minniti G, Salvador L, Bottio T, et al. The fate of Han cock II porcine valve recipients 25 years after implant. Eur J Cardiothorac Surg. 2010;38:141-6.

Key Words: bovine pericardial valve, surgical valve replacement, safety, effective orifice area, clinical trial 